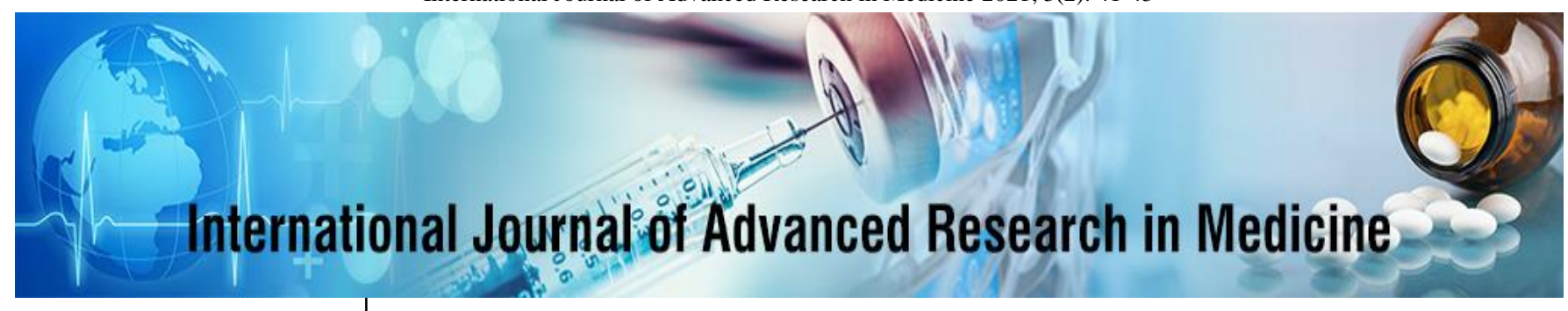

E-ISSN: 2706-9575

P-ISSN: 2706-9567

IJARM 2021; 3(2): 41-43

Received: 11-05-2021

Accepted: 18-06-2021

Dr. Ajmal Mir

MDS, Department of

Conservative Dentistry and

Endodontics, Govt Dental

College, Srinagar, Jammu and

Kashmir, India

Dr. Reyaz Farooq

MDS, Department of

Conservative Dentistry and

Endodontics, Govt Dental

College, Srinagar, Jammu and

Kashmir, India

Dr. Aamir Purra

MDS, Department of

Conservative Dentistry and

Endodontics, Govt Dental

College, Srinagar, Jammu and

Kashmir, India

Dr. Fayaz Ahanger

MDS, Department of

Conservative Dentistry and

Endodontics, Govt Dental

College, Srinagar, Jammu and

Kashmir, India
Corresponding Author:

Dr. Ajmal Mir

MDS, Department of

Conservative Dentistry and

Endodontics, Govt Dental

College, Srinagar, Jammu and

Kashmir, India

\section{Evaluation of the knowledge of dental practitioners regarding the present guidelines for the management of cardiopathic patients during endodontic treatment}

\author{
Dr. Ajmal Mir, Dr. Reyaz Farooq, Dr. Aamir Purra and Dr. Fayaz \\ Ahanger
}

DOI: $\underline{\text { https://doi.org/10.22271/27069567.2021.v3.i2a.280 }}$

\begin{abstract}
Background: Longer lifespans and advances in medicine have been matched by an increase in the prevalence of patients at risk of infection who are likely to receive endodontic treatment. The objective of this study was to assess knowledge of dental practitioners regarding the present guidelines for the management of cardiopathic patients during endodontic treatment.

Methods: This is a descriptive online survey, involving interviewing 200 dentists. The questions focused on the different types of heart disease and the indications or contraindications of endodontic therapy for the treatment of irreversible pulpitis. The questionnaire was calibrated and validated by the Scientific Committee.

Results: Almost all respondents reported knowledge of Infective Endocarditis (94.5\%) and focal infection (95.5\%).51.5 percent of respondents were unaware of high-risk heart disease (Group A) and lower-risk heart disease (Group B) $28 \%$ of the respondents did not find it necessary to establish a dialogue with the general practitioner.

Conclusion: A low level of knowledge of the current guidelines was found among dentists. Therefore, attempts should be made to teach the current guidelines in undergraduate/postgraduate dental education.
\end{abstract}

Keywords: endodontics, infective endocarditis, cardiac patients

\section{Introduction}

For a long time, the mouth cavity was thought to be the main bacterial entry point for many localised infections that spread to other parts of the body. In recent years, however, epidemiological and experimental studies have found a link between patients' poor dental health and their overall health. As a result, dental and periodontal infections, along with other risk factors such as smoking, obesity, physical inactivity, and age, are now considered risk factors ${ }^{[1]}$. If endodontic treatments with instrumental manoeuvres are not conducted effectively, germs may be released. These bacteria enter the bloodstream or lymphatic system and attach themselves to the endocardium. It's a tooth infection with a single source ${ }^{[2]}$. Germs can create difficulties in the heart, such as infective endocarditis. Bacterial endocarditis occurs in around a third of cases in otherwise healthy people, pleading for a global preventative strategy, particularly oral, that is tailored to the entire community ${ }^{[4,5]}$. Carrying out gestures that could produce bacteremia in cardiac patients with endocarditis, on the other hand, is a dangerous circumstance ${ }^{[6,7]}$.

Unfortunately, most of the previous studies conducted in other countries have shown a lack of consistency in the knowledge and practice of dentists in the management of cardiac patients ${ }^{[8]}$. The objective of this study was to assess knowledge of dental practitioners regarding the present guidelines for the management of cardiopathic patients during endodontic treatment.

\section{Methodology}

A total of 200 dental practitioners were enrolled in the present study. A self-administered questionnaire was distributed through online portals to a representative sample of dentists. The private, hospital associated and academics associated dental surgeons were enrolled. The demographics of the respondents were recorded, as well as their awareness of the 
current guidelines for preventing infective endocarditis, which were based on the consensus opinion of experts, and their sources of knowledge about that guidance. The inquiries centred on the various types of heart disease as well as the indications and contraindications for endodontic therapy in the treatment of irreversible pulp diseases.

\section{Statistical analysis}

SPSS v20.0 was used for data analysis. (SPSS v20.0 program, SPSS, Inc., Chicago, IL). The categorical data is presented as frequency distribution. The percentages were compared using the Chi square test. $\mathrm{P}<0.05$ was considered significant.

\section{Results}

A total of 200 participants were enrolled in the present online survey. 120 males and 80 females were recruited for the study. $40 \%$ of the study participants had an experience of more than 10 years. $69 \%$ dental surgeons were associated with the private practise. $90 \%$ of the participants stated that they received the initial knowledge from the undergraduate education.

Almost all respondents reported knowledge of Infective Endocarditis (94.5\%) and focal infection (95.5\%). 180participants $(80 \%)$ indicated that they were aware of the current Infectious Endocarditis Prevention Guidelines, and the most common source of this knowledge was their preservice training (Table 1). 51.5 percent of respondents were unaware of high-risk heart disease (Group A) and lower-risk heart disease (Group B) (Table 2). 51\% of the practitioners were not aware of the contraindications of endodontic treatment in cardiopathy. Antibiotic prophylaxis limited to 1 hour before treatment was not known to $73 \%$ of the participants. Finally, $28 \%$ of the respondents did not find it necessary to establish a dialogue with the general practitioner (Table 2).

Only $10 \%$ of the participants were using apex locator. 93.5\% study participants preferred manual preparation technique. When endodontic treatment was indicated, 19.5 $\%$ practitioners did not apply recommendations such as treatment in one session.

\section{Discussion}

Our sample is made up of 200 dental practitioners. Most of the dentists surveyed practiced in the private sector $69 \%$ (Table 1). The reason could be easy accessibility of the private practitioners than the one associated with the hospitals or academics. Most of the participants around $90 \%$ had received the knowledge during the initial training (Table 1). However, more than $51.5 \%$ of practitioners are unable to distinguish a heart patient from group A and group B. (Table 2). Our results were in accordance with those of Kazuma et al. ${ }^{[9]}$ who had shown in their study that in pediatric dentists in Japan, it was difficult to identify which cardiac diseases are at high risk, probably due to a lack of training in cardiology. Concerning the international recommendations on antibiotic prophylaxis one hour before the endodontic treatment, $73 \%$ of the participants do not know these recommendations (Table 2). This could be due to the modalities of prescription which remain little particular.
Our results are largely disproportionate compared to those of Errahmouni ${ }^{[10]}$ who noted that only half of the dentists in the city of Marrakech knew the antibiotic prophylaxis, contrary to $27 \%$ noted in our study. They observed a low level of knowledge of current guidelines among dentists for antibiotic prophylaxis. 19 Most of the molecules recommended for the antibiotic prophylaxis are from the $\beta$ lactam family (Ex: Amoxicillin). In our study, $73 \%$ participants were aware to prescribed $\beta$-lactams in accordance with the recommendations (Table 2). This result is close to that of Errahmouni which collected $74 \%$ of its sample ${ }^{[10]}$.

In addition, the study carried out by Kapitchet ${ }^{[11]}$ in 2017 on the prescription of antibiotics in endodontics showed a higher rate $(98.20 \%$ of prescriptions). Carrying out endodontic care in heart patients is very complex. In group A patients endodontic care should be exceptional. They can only be carried out after verification of the vitality of the tooth by appropriate tests. In addition, care must be carried out under a dike, in a single session, with an apex locator while being sure that all of the canal lumen is accessible. In any event, the idea of carrying out the treatment in a single session responds to a principle of minimizing the risks of colonization and/or decolonization of the endodontic by microorganisms. Only $19.5 \%$ of practitioners were aware of the concept of endodontic treatment in single session in high risk patients. (Table 3 ).

All these precautions are necessary to work in an aseptic environment and avoid introducing germs into the periapex. When evaluating endodontic procedures, our study found that only 12 and $10 \%$ participants use a dam or apex locator respectively (Table 3 ). Most dentists $(93.5 \%)$ used manual canal preparation techniques and $84 \%$ performed canal filling with the non-compressive technique (Table 3). However, it has been proven that these techniques do not guarantee the seal sought during endodontic treatment. Indeed, with manual canal preparation techniques, the major risk of bacteremia is located during the initial phase of treatment: when the instruments seeking to reach the working length through a channel whose taper has not been established, entrain and pack bacteria in an apical situation or even propel them in an extra-radicular situation ${ }^{[9]}$. This risk persists during shaping in the absence of adequate hypochlorite irrigation and during obturation in the event of non-compliance with the apical limits.

Table 1: Characteristics of the study population

\begin{tabular}{|c|c|c|}
\hline Parameters & $\mathbf{N}(\mathbf{2 0 0})$ & $\%$ \\
\hline \multicolumn{3}{|l|}{ Gender } \\
\hline Males & 120 & 60 \\
\hline Females & 80 & 40 \\
\hline \multicolumn{3}{|c|}{ Years of practise } \\
\hline $1-5$ years & 59 & 29.5 \\
\hline $5-10$ years & 61 & 30.5 \\
\hline More than 10 years & 80 & 40 \\
\hline \multicolumn{3}{|l|}{ Job sector } \\
\hline Private & 138 & 69 \\
\hline Academic & 22 & 11 \\
\hline Hospital & 40 & 20 \\
\hline \multicolumn{3}{|c|}{ Source of the knowledge } \\
\hline Undergraduate education & 180 & 90 \\
\hline During the working years & 20 & 10 \\
\hline
\end{tabular}


Table 2: The proportions of correct responses for each item for the questions

\begin{tabular}{|c|c|c|c|}
\hline Knowledge & Yes/No & Total Number & \% \\
\hline Infectious endocariditis & Yes & 189 & 94.5 \\
\hline Focal infections & Yes & 191 & 95.5 \\
\hline Group A and Group B & No & 103 & 51.5 \\
\hline Antibiotic prophylaxis & Yes & 52 & 26 \\
\hline Prescription of beta lactams (amoxicillin) & Yes & 146 & 73 \\
\hline Antibiotic prophylaxis one hour before endodontic treatment & No & 146 & 73 \\
\hline Dialogue with general practitioner & No & 56 & 28 \\
\hline Indications and contraindications for endodontic treatment & No & 102 & 51 \\
\hline Application of consensus recommendations & No & 101 & 50.5 \\
\hline
\end{tabular}

Table 3: Assessment of the endodontic procedure

\begin{tabular}{|c|c|c|c|}
\hline Procedures & Yes/No & Total No & $\%$ \\
\hline Use of dike & Yes & 24 & 12 \\
\hline Use of apex locator & Yes & 20 & 10 \\
\hline Manual preparation technique & Yes & 187 & 93.5 \\
\hline Compressive obturation technique & No & 168 & 84 \\
\hline Endodontic treatment in 1 session & Yes & 39 & 19.5 \\
\hline
\end{tabular}

\section{Conclusion}

The practise of endodontics cannot be imagined independent of the patient's medical setting. This defines the indication or contraindication for therapy, regardless of endodontic treatment feasibility and prognosis, based on local characteristics. When endodontic treatment is required, adherence to consensus recommendations and the implementation of good practise standards are critical for the practitioner to avoid potentially fatal infection complications. In patients at risk of infection from afar, the limitations and biomechanical constraints of endodontic treatment argue in favour of antibiotic prophylaxis. According to our research, only a small percentage of dental surgeons are aware of precautions to be taken during endodontic treatment in heart patients. Better still, the practical situation showed that in reality, almost all of the practitioners interviewed found it difficult to correctly apply the prescribed recommendations.

\section{References}

1. Cassia A, Toum SE. Endocardite infectieuse a porte d'entr ' ee orale. Rev Odontostomatol 2000;29(1):3342.

2. Li X, Kolltveit KM, Tronstad L, Olsen I. Systemic Diseases Caused by Oral Infection. Clin Microbiol Rev 2000;13(4):547-54.

3. Seymour RA, Lowry R, Whitworth JM, Martin MV. Infective endocarditis, dentistry and antibiotic prophylaxis; time for a rethink? $\mathrm{Br}$ Dent $\mathrm{J}$ 2000;189(11):610-6.

4. Baudet-Pommel M, Lusson JR, Bertoin P. Prophylaxie des endocardites infectieuses a porte d'entr `ee buccodentaire. Encyc lMed' Chir (Paris) 2000;R-12:10.

5. Persac $\mathrm{S}$. An update on focal infection of oral origin. Rev Stomatol Chir Maxillofac 2011;6:353-9.

6. Epstein JB. Infective endocarditis: dental implications and new guidelines for antibiotic prophylaxis. J Can Dent Assoc 1998;64(4):281-287.

7. Pallasch TJ, Slots J. Antibiotic prophylaxis and the medically compromised patient. Periodontol 1996;10(1):107-38.

8. Lacassin F, Leport C. L'endocardite infectieuse, ses facteurs de risque, sa prevention.' Reve Med Inter 1993;14(9):871-6.
9. Kazuma K, Ryota N, Takahiro O, Satoshi N, Kazuhiko N. Connaissances actuelles des specialistes de la dentisterie $\mathrm{p}$ ' ediatrique ' au Japon concernant la prevention de l'endocardite infectieuse. Pediatr Dent J 2018;28(2):110-7.

10. Errahmouni A. Enquete sur la Pratique de l'Antibioprophylaxie ^ de l'Endocardite Infectieuse (EI) par les Dentistes de la Ville de Marrakech. These pour obtention du doctorat en medicine 2009, 67.

11. Adou AJ, Atse-N'guessan KS, Adou-Assoumou M, Ndre J, Krah-Sinan AA, Mokiya J. Abidjan dentists' knowledge of the current guidelines for the management of cardiopathic patients during endodontic treatment. IP Indian J Conserv Endod 2020;5(2):44-47. 